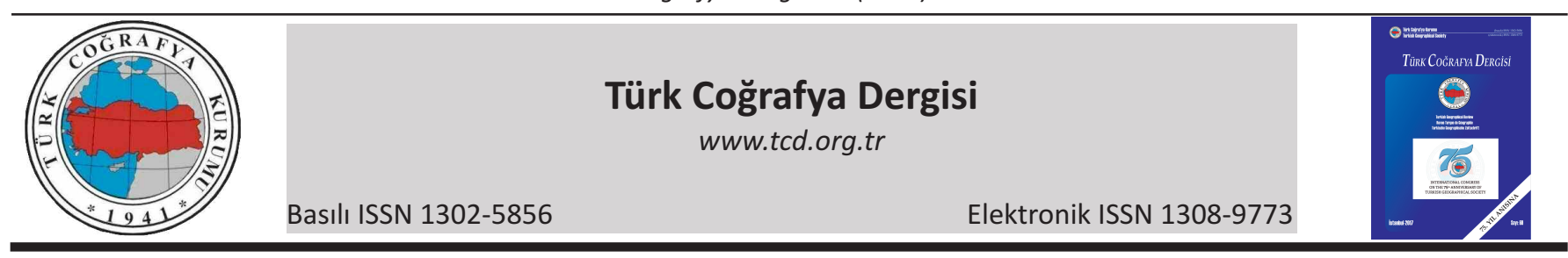

\title{
İnovasyon coğrafyasıda üniversitelerin rolünü analiz etmeye dönük bir yöntem önerisi
}

\section{A methodological proposal to analysis the role of universities in innovation geography}

\author{
İran Kaygalak*a (1) \\ ${ }^{a}$ Balıkesir Üniversitesi, Fen-Edebiyat Fakültesi, Coğrafya Bölümü, Balıkesir.
}

\section{BILGI / INFO}

Geliş/Received: 28.02.2017

Kabul/Accepted: 21.06.2017

Anahtar Kelimeler:

İnovasyon coğrafyası

Patent

Sosyal ağ analizi

Üniversite-sanayi işbirliği

Keywords:

Innovation geography

Patent

Social network analysis

University-industry collaboration

*Sorumlu yazar/Corresponding author

(i. Kaygalak) ikaygalak@hotmail.com

http://doi.org/10.17211/tcd.295458

\begin{abstract}
ÖZ / ABSTRACT
Bu çalışma Türkiye'de yenilikçi bilgi üretiminde ve yayılımında üniversitelerin rolünü incelemeyi amaçlamaktadır. Mevcut birçok çalışmanın aksine tanımlayıcı belli başlı göstergeler sunmak yerine, bu çalışma yenilikçi bilgi üretimini ve yayılımını söz konusu bu bilgiyi üreten ve yayan temel aktörler olan buluşçular arası ilişkilere odaklanarak incelemektedir. Dolayısıyla inovasyon süreçlerine ilişkin dinamik bir sorgulama yapmayı sağlayacak niceliksel ve analitik bir yöntem geliştirilebileceğini önermektedir. Çalışmanın temel bulguları Türkiye'nin yenilikçi bilgi üretiminde görece geri bir konumda olduğunu, hem attf bilgisi itibariyle hem de buluşçular arası ağın yoğunluğu itibariyle zayıf bir işbirliği ve bilgi transfer ağına sahip olduğunu ortaya koymaktadır. Ayrıca organizasyon türü açısından üniversitelerdeki buluşçuların özel sektördekilerine kıyasla belli dereceler açısından daha düşük göstergelere sahip olduğu ve yenilikçi süreçlerde beklenilen performansı ortaya koymadıkları görülmektedir. Buna karşın ele alınan sektör itibariyle özel sektör buluş̧̧ularının daha yoğun bir ağa sahip olduğu ve değişik göstergeler itibariyle yenilikçi bilgi üretim sürecinde üniversite mensubu buluşçulardan daha yüksek bir performans sergilediği görülmektedir.
\end{abstract}

This study aims to examine the role of universities in innovative knowledge production and innovation in Turkey. Contrary to previous studies that present descriptive indicators related to innovation, the study investigates role of universities by concentrating on collaborative network of inventors those play key role in knowledge production and dissemination. Therefore the study proposes a quantitative analytical framework that able to comprehend dynamics of innovation processes in Turkey can be improved. The findings of study reveal that Turkey is relatively lagged in innovation and network between inventors in innovative knowledge production is considerably weak. Weak ties between inventors appear as significant obstacle in terms of innovative knowledge spillovers. Besides, in terms of organizational proximity university member inventors perform weaker connection on collaboration networks and there are considerable differentiations between them and other inventors those working in business. The results indicate inventors who are not affiliated with universities perform higher values in terms of diverse measures of social network of innovative knowledge production.

\section{Giriş}

Küreselleşme ve ulusal ekonomilerin liberalizasyonu ile birlikte serbestleşen mal, hizmet ve işgücü akışı beraberinde değişik türde bilginin de aktörler ve bölgeler arasında yayılımını kolaylaştırmıştır. Bilgi akışındaki kolaylık salt onun taşıyıcı kanalları olan teknolojik gelişmelerin değil, fakat ekonomik üretimin değişen örgütlenme biçimiyle de bağlantılıdır. Ekonomik üretimdeki esnek uzmanlaşma üretim ağı üzerinde yer alan değişik aktörlerin ve bölgelerin zorunlu işbirliğine ve bilgi paylaşımına neden olmaktadır (Piorre ve Sabel, 1984; Cooke ve Morgan, 1998). Yeni ekonominin değişen doğası bilgiyi üretimin en önemli kaynağı, öğrenmeyi de en önemli süreci kılmaktadır (Lundvall, 1992). Bilginin bölgesel ekonomik gelişme ve rekabetçilik düzeyinde temel belirleyen olarak vurgulanmaya başlanması, ekonomik coğrafya literatüründe söz konusu bilginin üretimi ve yayılımı konusunda yeni bir araştırma gündeminin belirmesine neden olmuştur.

Ekonomik coğrafyanın bir alt dalı olarak beliren bu yeni araştrrma gündemi inovasyon coğrafyası olarak bilinmekte ve temelde yenilikçi bilginin üretimi ile yayılımına odaklanmaktadır. Son yıllarda ekonomik coğrafyacılarca bilginin ve yenilikçiliğin mekansal doğasını anlamaya dönük çalışmaların sayısı giderek artmaktadır (Capello, 1999; Gertler, 2003; Boschma, 2005; Knoben ve Oerlemans, 2006; Boschma ve Frenken, 2010). Bu çaışmaların genel bir değerlendirmesi yapılacak olursa yenilikçiliğin mekansal boyutunun belli eksenler etrafinda incelendiği göze çarpmaktadır. Bunlardan birincisi yenilikçi bilgi üretiminin yuvaları olarak görülen ve literatürde "kuluçka" ola- 
rak değerlendirilen yenilikçi mekanların varlığı ve bunlara has niteliklerdir. Yenilikçi bilginin üretim ve yayılım açısından mekansal seçiciliğine vurgu yapan bu tür çalışmalarda esas vurgu, yenilikçiliğin doğası gereği her yerde olmayan belli başlı bazı temel nitelikleri taşıyan, beşeri sermayesi ve kurumsal işleyişi ile fark yaratıcı etkiye sahip özel coğrafyalarda olduğuna ilişkindir (Audretsch ve Feldman, 1996). İkinci bir araştırma ekseni olarak gerek bu kuluçkalarda gerekse diğer bölgelerde yenilikçi bilginin üretiminde kritik rol oynayan üniversitelerin ve diğer kurumsal varlıkların rolü zikredilebilir.

Literatürde üniversitelerin bu kritik rolü üçlü sarmal adı altında kavramsallaştırımakta ve yenilikçi atmosferin oluşmasında üniversitelere kurucu rol atfedilmektedir. Gerek her türlü yenilikçi bilginin üretimini sağlayacak insan kaynağının yeniden üretimi açısından, gerekse gerekli kurumsal işleyişin oluşturulması açısından artan önemi nedeniyle üniversiteler ve üstlendikleri roller başlı başına birer ayrı çalışma konusu olmaktadırlar. Bu kapsamda üniversite sanayi işbirliği yenilikçi bölgeler üzerine yapılan değerlendirmelerde en önemli bileşenlerden biri olarak ele alınmaktadır (Leydesdorff ve Etzkowitz, 1996; Soetanto ve Geenhuizen, 2011).

Yenilikçi bilginin mekansal boyutuna ilişkin bir başka değerlendirme ekseni ise yenilikçi bilgi üretimi ve yayılımının endüstriyel yığılma ve kümelenmelerle olan ilişkisi üzerinedir. Son yıllarda ekonomik coğrafyada yaygın bir araştırma gündemi olarak beliren kümelenme çalışmaları, özellikle endüstriyel kümelenmelerin yenilikçi bilgi üretim ve yayılım alanları olarak ön plana çıktı̆ını savunmaktadır (Renski, 2012; Bathelt vd., 2004; OwenSmith ve Powell, 2004; Giuliani ve Bell, 2005). Nitekim yenilikçi bilgi üretimi ve yayılımının endüstriyel kümelerle olan sıkı ilişkisi nedeniyle, ekonomik coğrafya içinde bu konuyla ilgili araştırmalar artmış ve inovasyon coğrafyası başlı başına ayrı bir disiplin olarak ortaya çıkmıştır.

Son olarak bilgi türleri ile bilginin değiş̧ik aktörler ve bölgeler arasında yayılımını kolaylaştıran ya da güçleştiren etkenler bir başka araştırma eksenini oluşturmaktadır. Başta kodifiye ve örtük bilgi ikileminin genel karakterinden hareket eden bu tür çalışmalar, söz konusu bilgi yayılımının önsel koşulları olarak aktörler arasındaki bilişsel, coğrafi, kültürel, sosyal, organizasyonel ve kurumsal mesafelerin etkisine vurgu yapmakta; yenilikçi bilgi yayılımın gerçekleşebilmesi için aktörler arasında bahsedilen değişik türdeki mesafelerin önemli bir koşul olduğunu savunmaktadırlar (Audretsch ve Aldridge, 2009; Boschma, 2005; Bathelt vd., 2004). Benzer şekilde bölgeler ve endüstriler arası bilgi transferi için de söz konusu mesafelerin rolüne değinilmekte ve özellikle bölgelerin sahip olduğu sektörel yapıdan kaynaklanan bilgi tabanlarının bilgi yayılımını belirleyen önemli bir faktör olduğu savunulmaktadır (Asheim vd., 2007).

Yabancı literatürde inovasyon coğrafyasının araştırma gündemi bu dört ana eksen etrafinda olurken, Türkiye'de inovasyon coğrafyası ile ilgili çalışmaların yaygın olmadığı göze çarpmaktadır. İnovasyon coğrafyasına ait kavramsal ve kuramsal değerlendirmeler daha çok coğrafyacılar dışındaki araştırmacılarca kullanılmakta ve takip edilmektedir (Durgut ve Akyos, 2001; Altnnok vd., 2004; Elçi vd., 2008; Sungur ve Keskin, 2009; Dulupçu ve vd., 2010; Varol vd., 2011; Eyyuboğlu ve Aktaş, 2016). Ne lisans ne de lisansüstü düzeyde coğrafya bölümlerinde inovasyon coğrafyası ile ilgili derslerin olmayışı da coğrafyacıların böylesine güncel ve popüler olan alana mesafeli durduklarına kanıttır. Bunun yanı sıra Türkiye'de inovasyonun coğrafi boyutuna eğilen çalışmalara bakıldığında bunların daha çok kuramsal değerlendirmeler düzeyinde kaldığı ve ampirik verilere dayalı niceliksel yöntemleri de içeren ayrıntılı çalışmaların olmadığı görülmektedir.

Oysa üniversiteler bölgesel inovasyon sistemleri ve ulusal inovasyon sistemleri içinde en önemli kurumsal aktör olarak zikredilmektedirler (Mowery ve Sampat, 2006). Çünkü sadece temel araştırma alanında değil, sanayi ve hizmetler alanındaki her türlü yeniliğin üretimi ve ticarileşmesi ayağında da üniversiteler geçmişte olduğundan daha kritik bir role sahiptirler. Bu kapsamda üniversite-sanayi işbirliği, bölgesel ve ulusal ekonomik kalkınmanın önsel koşullarından biri olmaktadır. Nitekim bu yüzden üniversitelerin yenilikçi bilgi üretimindeki rolü, yenilikçilik politikalarının da önemli bir eksenini oluşturmakta olup pratikte "bilim parkı", "teknokent" veya "teknopark" gibi uygulamalarla yaşama geçirilmektedir (Varol vd., 2011; Eyyuboğlu ve Aktaş, 2016). Ancak Türkiye'de inovasyonun coğrafi boyutlarına ilişkin niceliksel araştırmalar yapabilecek teknik ve yöntemlerin pek bilinmemesi, böylesi niceliksel araştırmalara kaynak oluşturacak ulusal bilgi kaynaklarının sınırlı oluşu ve konunun daha çok politika ayağına ilişkin kaygılar ile ele alınması nedeniyle üniversitelerin rolünü ampirik olarak analiz etmeye dönük çalışmalar sınırlı olmaktadır.

Bu çalışmada yenilikçi bilginin üretiminde üniversitelerin rolü Türkiye örneğinde tartş̧ımakta ve üniversitelerin yenilikçi bilgi üretimindeki rolünü analiz etmeye dönük yeni bir yöntem önerisi sunulmaktadır. Bu amaçla çalışmanın takip eden bölümünde yöntem ve veri ele alınmakta, bir sonraki bölümünde ise analiz sonuçları ve bulgular tartışılmaktadır. Genel bir değerlendirme ve alternatif araştırma gündemi ise sonuç bölümünde sunulup tartışılmaktadır.

\section{Yöntem ve Veri}

Yenilikçi bilginin üretimi ve yayılımının coğrafi boyutlarını belirlemeye dönük çalışmalar görece yenidir. Bundaki temel nedenlerin başında bilginin aktörler ve bölgeler arasında transferi ve yayılımı sırasında "iz bırakmaması" gelmektedir (Krugman, 1991:53). Ancak son yıllarda hem bilgi üretiminin göstergesi hem de bilgi yayılımının göstergesi olarak patent verileri bu sorunun üzerinden gelmek için kullanılmaktadır. Patent dokümanları, sahip oldukları bilgi kaynağı nedeniyle hem aktörlere hem de bu aktörlerin mekansal boyutlarına ilişkin detaylı veri sunmaktadırlar. Patent başvurusunu yapan firma, kişi ve kurum isimleri, adresleri, buluşçuların kimlik ve adres bilgileri, kurum bilgileri, patentin alındığı teknolojik sınıflar ile yine bu patentlerin üretimi sırasında yararlanılan kaynakların ya da atfların varlığı, patentleri bilgi yayılımının mekansal boyutlarını anlamak için vazgeçilmez kaynaklardan biri yapmaktadır. Bu da ekonomik coğrafyacıların patent verilerinden hareketle bilgi üretim ve yayılımının coğrafi boyutlarına dair araştırmalar yapmasını mümkün kılmaktadır.

Özellikle adres bilgilerinin varlığı, yenilikçi bilginin üretiminde ve yayılımında mekansal bir yoğunlaşma ya da yerelleşme eğilimi olup olmadığına imkan vermektedir. İlk olarak Jaffe vd., (1993) tarafindan patentlerin atf bilgisinden yola çıkılarak yenilikçi bilgi yayılımında yerelleşme eğiliminin olup olmadığı sorgulanmıştır. Literatürde JTH (Jaffe-Trajtenberg-Henderson) yöntemi ya da eşleştirme yöntemi olarak bilinen bu yolla atf yapan patentler ile atfı yapılan patentlerin coğrafi eşleştirmesi 
yapılmakta ve her ikisi arasındaki eşleşme düzeyi kontrol grubu patentten daha fazla olması durumunda bilgi yayılımında yerelleşme göstergesi olarak alınmaktadır (Ayrınt için Jaffe vd., 1993; Thompson ve Fox-Kean, 2005 ile Breschi ve Lissoni, 2003'e bakılabilir). Ancak atıfların coğrafi eşleşme düzeyleri üzerinden yapılan bu tür sorgulamalarda sayıca fazla miktarda patent verisine ihtiyaç duyulduğundan Türkiye gibi patent sayısının az olduğu ülkeler için kullanımı mümkün değildir.

Bu yüzden patent verilerinden hareketle yapılacak bir analiz için attf bilgisinden ziyade yenilikçi bilgi üretiminin aktörleri arasındaki ilişkiden yola çıkılarak yapılacak bir analiz daha anlamlı olmaktadır. Kaldı ki yenilikçi bilgi üretiminin dinamiklerini anlamak açısından da bilgi üreticilerinin ya da taşıyıcılarının arasındaki ağı incelemek aynı zamanda bu süreçlerde etkili olan değişik mesafelerin etkisini de anlamaya imkan vermektedir. Bu yüzden yenilikçi bilginin üreticisi olan ve patent üzerinde kimlik, kurum, adres ve diğer bilgileri bulunan buluşçuların sosyal ağı tek çözüm yolu olarak kalmaktadır. İlk defa Breschi ve Lissoni (2003) tarafindan kullanılan bu yöntemle coğrafyacılar, yenilikçi bilginin mekansal boyutları yanı sıra bilgi taşıma kanalları üzerinde de sorgulama yapma şansı kazanmışlardır. Breschi ve Lissoni (2003), her bir patenti o patenti üreten buluşçuların işbirliği yaptıkları proje olarak kabul etmekte ve bu proje ortakIığından hareket ederek buluşçular arası ilişkinin matrisini çıkarmışlardır. Buluşçular arası ilişkiyi gösteren matrisin elde edilmesinden sonra bu matris sosyal ağ analizi yöntemi ile haritalanmakta ve değişik parametreler itibariyle sorgulanabilmektedir. Böylece patent verilerinden hareketle buluşçular arası ağın sosyal ağ analizine tabi tutulmasıyla hem her bir buluşçunun bilgi üretimi ve yayılımındaki rolü hem de bu buluşçuların adresleri aracılığıyla söz konusu üretimin ve yayılımın coğrafi boyutu analiz edilebilmektedir (Yöntemin şematik ve daha ayrıntılı gösterimi için bakınız Breschi ve Lissoni, 2003).

Bu çalışma da aynı yöntemi kullanarak Türkiye'de ilaç sanayisi (farmakoloji) sektöründe yenilikçi bilgi üretiminde rol alan buluşçuların ağından hareketle üniversitelerin rolünün incelenebileceğini önermektedir. Bu amaçla Avrupa Patent Ofisi'ne (EPO) ve Amerika Patent Ofisi'ne (USPTO) kayıtlı, Türkiye'den başvurusu yapılmış olan ilaç sektörüne ait patentler çalışmanın temel verisi olarak kullanılmıştır. Türkiye Patent Enstitüsü’ne (TPE) ait veriler her ne kadar sektörel bazda her bir yıl için yapılan patent başvuru sayılarını, ilan tarihlerini ve il menşelerini gösteriyorsa da bu çalışmada önerilen yöntemin gereksindirdiği diğer ayrıntılı bilgileri içermemektedir. Yukarıda bahsedilen patent dokümanları üzerindeki ayrıntılı bilgilere erişime izin vermemesi ve daha da önemlisi bu bilgilerin sayısal ortama aktarılmamış olması TPE verilerini bu tür çalışmalara uygun olmaktan çıkarmaktadır. Bu nedenle bu çalışma TPE verilerini dışarıda bırakmak ve sadece EPO ile USPTO'ya kayıtlı ve Türkiye'den başvurusu yapıımış patent dokümanlarını içermek zorunda kalmıştır.

EPO kayıtlarına göre 1987 ve 2014 yılları arasında farmakoloji alanında Türkiye'den başvurusu yapılıp ilan edilmiş olan toplam 325 adet patent bulunmaktadır. Aynı sayı 1992 ile 2014 yılları arasını kapsayan dönemde USPTO için 97 adettir. Ancak bu her iki patent ofisinin kayıtlarını karşılaştırdığımızda bu patentlerin bazılarının aynı olduğu, yani aynı patent için her iki ofise de başvuru yapıldığı görülmektedir. Bu türdeki tekrarları eledikten sonra USPTO'ya kayıtlı 48 ve EPO'ya kayıtlı 325 patent olmak üzere çalışma kapsamına toplam 373 patent dâhil edilmiştir.
Şekil 1'de de görüldüğü gibi bu patentlerin yayın tarihleri itibariyle dağılışı çok düzensizdir. Özellikle 2005 yılı öncesinde Türkiye'den bu patent ofislerine yapılan patent başvuru ve kabul sayısının çok az olduğu görülmektedir. Söz gelimi 1994, 1995, 1997 ve 2002 yıllarına ait yayınlanmış yani kabul edilmiş herhangi bir patent bulunmamaktadır. Buna karşın patent sayısındaki asıl gelişme 2008 yılından sonra olmaktadır. Bunun temel nedeni yabancı patent ofislerine başvurunun maliyetli olması ve dil gibi engeller nedeniyle başvuru koşullarının güç olmasıdır. Yakın zamanda TÜBITAK, KOSGEB ve üniversiteler aracılığıyla firma ve tekil kişilere patent başvurularında danışmanlık hizmeti verilmesi ve patentleme süreçlerinin mali açıdan desteklenmesi 2008 yılından sonra EPO'ya ve USPTO'ya yapılan başvuruların artmasında etkili olmuştur.

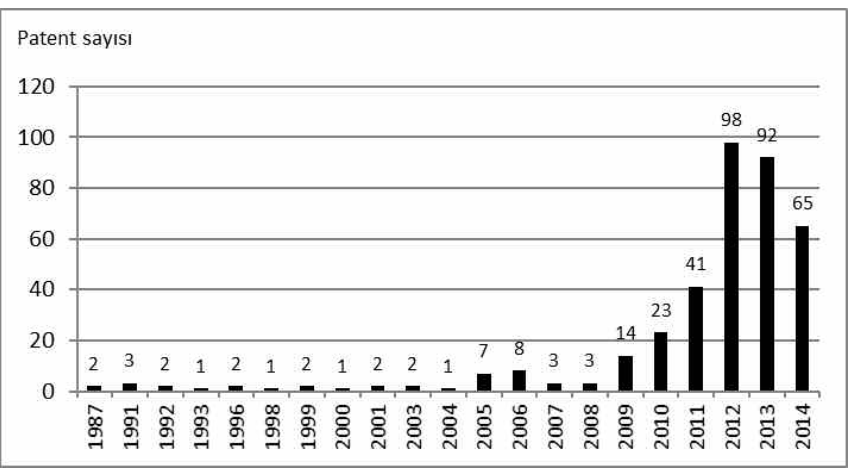

Şekil 1. EPO ve USPTO'ya kayıtlı patent sayıları (1987-2014).

Figure 1. Patent numbers registered at EPO and USPTO (1987-2014).

Bu çalışma kapsamında kullanılan, 1987 ile 2014 yılları arasında EPO'ya ve USPTO'ya kayıtlı bu patentlere ait buluşçu sayısı ise 282 'dir. Ancak 27 yıllık gibi görece uzun sayılabilecek bu zaman diliminde bulunan buluşçuların bazılarının emekli olduğu ya da hayatta olmadığı göz önüne alınarak son dönem yenilikçi bilgi üretiminde doğal olarak rol alamayacakları varsayılabilir. Nitekim Breschi ve Lissoni (2013) ile Boschma ve Ter-Wal (2009) bu nedenle buluşçular arası ağın orta ve kısa vadeli olarak analiz edilmesinin daha gerçekçi bir resim elde etmeye olanak sunduklarını savunmaktadırlar. Hem bu durum nedeniyle hem de patent başvurularının daha çok son yıllarda yoğunlaşması nedeniyle 1995 yılı ve sonrasına ait patentlerin üretiminde rol alan 245 buluşçu analize dâhil edilmiştir.

Uluslararası Patent Sınıflandırmasına göre kimya ve metalürji segmentinde yer alan ilaç sanayisi aynı zamanda bu segmentteki en fazla başvuruyu temsil etmektedir. Ayrıca kimya ve metalürji segmentinin diğer alt sektörleriyle kıyaslandığında ilaç sanayisi yenilikçilik düzeyinin daha yüksek olması beklenilen bir sektördür. Üstelik bu sektördeki yenilikçiliğin üretimi farmakologlar, doktorlar ve kimyagerler başta olmak üzere değişik bölümlerdeki üniversiteli akademisyenlerin işbirliğini gerektirdiğinden üniversitenin yenilikçi bilgi üretimindeki rolünü sorgulamaya en uygun sektördür. Bu yüzden bir yöntem önerisi sunan bu çalışmanın amacına uygun sektörü temsil etmektedir.

Bu nedenle ilaç sektöründeki söz konusu buluşçuların ağından yola çıkarak yenilikçi bilgi üretiminde ve yayılımında üniversitelerin rolü test edilebilir. Bu kapsamda patent bilgisinden yola çıkarak aynı patentin üretiminde rol alan buluşçular ortak proje üyesi olarak kabul edilmiş ve her bir patent ile ilişkili oldukları buluşçuların bağını gösteren ilişki matrisi oluşturulmuştur. Bu- 
luşçu-patent matrisi oluşturulduktan sonra bu matristen hareketle buluşçuların birbirleriyle olan ilişkisini gösteren sosyal ağ haritası elde edilmiştir. NetDraw ve UCINET sosyal ağ analizi yazılımlarıyla elde edilen bu buluşçular ağ haritasından sonra, ağdaki her bir buluşçuya ait öz nitelikler atanmıştır. Patent dokümanı üzerinde bulunan adres bilgisi ve kurum bilgileri öz nitelik tablosuna aktarıldıktan sonra sosyal ağ analizinde kullanılan değişik göstergeler itibariyle analiz yapılmış ve her bir buluşçunun mevcut ağdaki konumu değişik parametreler itibariyle sorgulanmıştır.

Patent dokümanları üzerinde buluşçuların kurum bilgisinin bulunması hangi buluşçunun üniversite üyesi olup olmadığını belirlemeye imkan vermektedir. Bu yüzden buluşçular özel sektör üyesi ve üniversite üyesi şeklinde ikili bir kategoriye ayrılmış ve belirtilen yazılımlar aracılığıyla bilgi üretim ağındaki konumlarında anlamlı bir farklılaşma olup olmadığı merkezilik derecesi, yoğunluk, yakınlık ve arasındalık parametreleri gibi sosyal ağ analizi yönteminde sıklıkla kullanılan göstergeler itibariyle sorgulanmıştır. Gruplar arasındaki farklılaşma ise T-testi ile incelenmiştir. Türkiye'de normal eğitim veren üniversitelerin yanı sıra araştırma odaklı teknik üniversitelilerin rolünü ayrıca sorgulamak için ise üniversiteli buluşçular normal üniversiteli ve teknik üniversite çalışanları biçiminde de ikiye ayrılmış ve aynı parametreler itibariyle gruplar arası farklılaşmanın olup olmadığı ANOVA testi ile incelenmiştir.

\section{Bulgular}

İlaç sektöründeki buluşçuların sosyal ağ haritasına bakıldığında belli başlı noktalar göze çarpmaktadır. İlk olarak EPO ve USPTO kayıtlarına göre ilaç sektörüne yapılan patent başvuruların büyük bir bölümünün daha çok büyük ölçekli birkaç firma tarafindan yapıldığı görülmektedir. Dolayısıyla sektördeki yenilikçi bilgi üretiminde firma bazında ciddi bir yoğunlaşma göze çarpmaktadır. Bunlar genel olarak Türkiye'de sektörün iyi bilinen öncü firmaları olup coğrafi açıdan aynı bölgede yer almaktadırlar. Söz konusu patentlerin sahibi olan firmaların dağılışına bakıldığında bunların çoğunlukla İstanbul, Kocaeli, Düzce ve Kırklareli'nde yer aldığı görülmektedir. Buna karşın bu patent üreticisi olan buluşçuların ikametgâh adresleri de her ne kadar bu illerle büyük oranda örtüşüyorsa da İzmir, Antalya ve Ankara başta olmak üzere Marmara Bölgesi dışındaki birkaç ile kadar uzanabilmektedir. Ancak hala asıl yoğunluk İstanbul başta olmak üzere Marmara Bölgesi lehine olmaktadır.

Önemli bulgulardan biri de ilaç sektöründeki yenilikçi bilgi üretiminde, üniversiteli buluşçulardan ziyade özel sektör çalışanı buluşçuların sayısal anlamda üstün olmasıdır. Öyle ki ele alınan 1995-2014 dönemi içindeki toplam 245 buluşçunun yalnızca \%10.6'sı (26 kişi) üniversite mensubu buluşçulardan oluşmaktadır. Bu rakam görece düşük bir sayıdır. Ancak Araştırmacı İlaç Firmaları Derneği'nin 2008 yılı verilerine göre Türkiye'de 64'ü üretici olan toplam 110 adet ilaç firması bulunmaktadır. Doğal olarak ilaç üreticisi konumunda olan bir ülkede sektör mensubu buluşçunun patent sahipliği açısından daha fazla olması beklenilir. O yüzden bir başına \%10.6 gibi bir değer düşük bir rakama denk gelse de üniversiteli buluşçuların sektördeki yenilikçi bilgi üretim itibariyle konumlarına dair çok fazla şey ifade etmemektedir.

Eğer amaç üniversiteli buluşçuların bilgi üretiminde ve yayılımında kritik rol alıp almadıklarını anlamaksa, bunun için bu- luşçu sayısından ziyade bilgi üretim ağı içindeki konumlarına bakmak daha anlamlıdır. Üniversiteler yeniliğe kaynaklık eden teorik bilginin üretimi yanı sıra bu yeni bilginin ticarileşmesine de ön ayak olan kuruluşlar olduğundan üniversite mensubu buluşçuların bilgi üretim ağı içinde daha merkezi konumda olmaları, köprü konumunda bulunmaları ve diğer buluşçularla olan jeodezik mesafelerinin daha kısa olması beklenilir. Bu yüzden söz konusu bu merkezilik konumunu gösteren değişik göstergelerin test edilebileceği sosyal ağın kendisinin analizi daha anlamlıdır.

Söz konusu patentlerin üreticisi olan 245 buluşçunun sosyal ağ haritası Şekil 2'de verilmiştir. Sosyal ağ analizinin temel göstergelerinden biri olan ağın küme-component sayısına bakıldığında ele alınan ağın 39 kümeden oluştuğu görülmektedir. Buna karşın söz konusu ağın en büyük küme-component üye sayısı ise 42'dir. Bilindiği gibi aktörler arası bağlantının güçlü olduğu bir sosyal ağda küme-component sayısının az olması ve en büyük kümenin üye sayısının da fazla olması beklenir (Wasserman ve Faust, 1994; Hanneman ve Riddle, 2016). Gerek küme-component bileşimi itibariyle gerekse diğer göstergeler açısından buluşçular ağının çok izole olduğu görülmektedir. Nitekim buluşçuların sosyal ağının genel yoğunluk derecesi 0.006 gibi çok düşük bir değer göstermektedir. Buna karşın sosyal ağ haritası üzerindeki erişilebilir aktörler arasındaki jeodezik mesafe 2,301; ağın ortalama merkezilik değeri 1,622 veya $\% 3,57$ düşük bir değer sergilemektedir. Dolayısıyla ağın genel yapısına ilişkin bu göstergeler sektördeki bilgi üretim süreçlerinde aktörlerin birbirinden yalıttk olarak çalıştıklarını gelişmiş ülkelerdeki örnekleriyle kıyaslandığında zayıf bir işbirliğinin olduğunu göstermektedir. Her ne kadar yer darlığı nedeniyle buluşçuların her bir yıla ait sosyal ağ haritalarını burada sunamazsak da, ağın zamansal analizine bakıldığında buluşçular arası bağlantının son yıllarda artma eğiliminde olduğu belirtilmelidir. Özellikle 2005 sonrası sosyal ağda buluşçular arası jeodezik mesafe kısalmakta, küme-komponent sayısı azalmakta ve yine network merkezilik düzeyi artmaktadır.

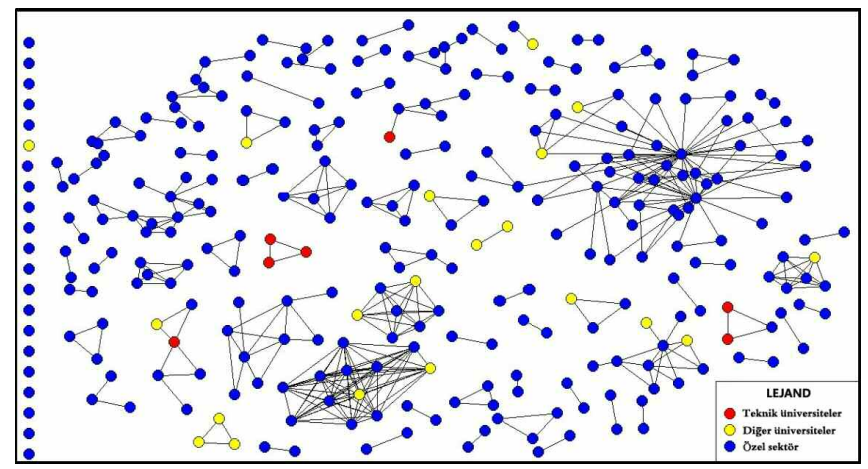

Şekil 2. Buluşçuların sosyal ağ haritası.

Figure 2. The map of social network of inventors.

Yenilikçi bilginin üretimi ve yayılımı açısından bakıldığında bir ülkedeki ya da bölgedeki aktörler arası bağlantının güçlü olması hem üretim hem de bilgi transfer süreçlerinin en önemli koşullarından biridir (Graf, 2006). Bu bağlantısallıkta özellikle üniversitelerin hayati rol oynadığı; coğrafi açıdan birbirine yakın olan aktörlerin diğer aktörlere göre daha yoğun bir ağa sahip oldukları savunulmaktadır. Benzer şekilde belli endüstriyel kümeler içinde yer alan aktörlerin hem bilgiye ulaşma kanallarının daha güçlü olduğu hem de bilgi yayılımı süreçlerine daha kolay dahil olabildikleri savunulmaktadır (Powell vd., 1996). Bu düşünce- 
den hareketle Kaygalak ve Reid (2016) sadece EPO verilerine dayalı olarak Türkiye'de ilaç sektöründe yenilikçi bilgi üretiminde endüstriyel kümelenmenin ve coğrafi yakınlığın önemli olup olmadığını test etmişlerdir. Benzer şekilde buluşçular arası sosyal ağ analizi yöntemini kullanan Kaygalak ve Reid (2016), buluşçuların arasındalık-betweenness, merkezilik-centrality ve yakınlık-closeness değerlerini inceleyerek küme üyesi olan buluşçular ile küme üyesi olmayan buluşçular arasında bu göstergeler itibariyle istatistiksel olarak geçerli bir farklılaşma olduğu sonucuna varmışlardır. Tablo 1'de de görüldüğü üzere coğrafi açıdan birbirine yakın olan küme üyesi buluşçuların ağdaki yakınlık-closeness değeri ve dolayısıyla bilgi üretim ağındaki kritik konumu diğer buluşçulardan istatistiksel olarak geçerli bir farkIılaşma göstermektedir $\{\mathrm{t}(231)=-2.730 ; \mathrm{p}>0.05\}$.

Bir sosyal ağda yakınlık-closeness ölçeği aktörlerin ağ konumundaki kilit rollerine ve bağlantılılık düzeylerine işaret etmektedir (Gürsakal, 2009). Buna göre yakınlık derecesi yüksek olan buluşçuların diğer buluşçulara erişim gücü daha fazla olup yenilikçi bilgi üretiminde ve bilginin yayılımında daha kritik ve belirleyici rol oynadıkları söylenebilir. T-testi sonucu küme üyesi olan buluşçular ile olmayan buluşçular arasında yakınlık derecesi itibariyle birincilerin lehine istatistiksel olarak anlamlı bir farklılaşma olması, ilaç sektörü örneğinde endüstriyel kümelenmenin ve coğrafi yakınlığın buluşçular arası etkileşimi ve işbirliğini arttırdığını ve dolayısıyla da bilgi paylaşım ve transfer süreçlerini de kolaylaştırdığına işaret etmektedir.

Benzer şekilde buluşçular arası yakınlık-closeness değerinin üniversiteli olanlar ve olmayanlar biçiminde sorgulanması da üniversitelerin bilgi üretim süreçlerinde belirleyici rol oynayıp oynamadıklarını gösterebilir. Bu amaçla üniversite mensubu buluşçular ile özel sektör çalışanı buluşçular arasında ikili bir ayrımdan yola çıkarak ağdaki konum itibariyle gruplar arası farklılaşma olup olmadığı T-testi ile sorgulanabilir. Tarafimızca EPO ve USPTO verilerine dayanılarak 1995-2014 dönemi ve ilaç sektörü için yapılan bu testin sonuçları Tablo 2'de sunulmuştur.

Tablo 2'de de görüldüğü üzere üniversiteli buluşçu sayısı 26 olup toplam buluşçu sayısının küçük bir bölümünü oluşturmak- tadır. Yukarıda da değinildiği gibi salt buluşçu sayısı itibariyle bakıldığında bile üniversite ile ilaç sanayisi arasında güçlü bir işbirliğinin olmadığı sonucuna varılabilir. Fakat daha analitik bir perspektifle bakıldığında ağdaki konumsal farklılaşmalarının daha anlamlı olduğu söylenmelidir. Bu amaçla Tablo 2'ye bakıldığında iki grup ortalaması arasında kayda değer bir farklılaşma görülmemektedir. Oysa bilgi üretim süreçlerinde üniversitelerin kilit konumda olması üniversite mensubu buluşçuların değişik parametreler açısından daha yüksek bir bağlantılılık düzeyine sahip olmasını gerektirir. Türkiye'de ilaç sanayisi örneğinde bu görülmemektedir. Her ne kadar istatistiksel olarak geçerli olmasa da $\{\mathrm{t}(242)=-0.089 ; \mathrm{p}>0.05\}$ üniversiteli buluşçular ile özel sektör buluşçularının sosyal ağ içindeki ortalama yakınlık-closeness değerlerinin dikkate değer bir farklılaşma göstermediği görülmektedir. Nitekim bu durum yukarıda değinilen buluşçuların sosyal ağ haritasının (sosyogram) yapısal özellikleriyle de uyumlu bir sonuçtur.

Türkiye'de üniversite sanayi işbirliği konusunda özellikle teknik üniversitelerin daha etkin olması beklenilir. Teknik üniversitelerin bu ayrıt edici rolünün olup olmadığını sorgulamak için ise buluşçuların özel sektör mensubu, teknik üniversite mensubu ve normal üniversite mensubu olarak üçlü kategoriye göre analiz edilmesi gerekmektedir. Bu amaçla bu üç kategorideki buluşçuların yakınlık, arasındalık, merkezi derecelik ve yine onun göstergelerinden bir olan eigen-vektör göstergeleri itibari ile yapılan analiz sonuçları Tablo 3'te sunulmuştur. Her ne kadar istatistiksel olarak geçerli olmasa da buluşçular arasındaki faklılaşmanın bütün göstergeler itibari ile olduğu görülmektedir. Buradaki en çarpıcı sonuç ise araştırma ve geliştirme çalışmalarına öncelik verdiği savunulan teknik üniversitedeki buluşçuların ele alınan göstergeler itibariyle çok zayıf olmasıdır. Bir başka deyimle yenilikçi bilgi üretim süreçlerinde üniversiteler genel olarak daha geri bir konumda olmasına rağmen teknik üniversiteler bunda daha da geri bir konumda bulunmaktadırlar.

Teknik üniversiteli buluşçuların ele alınan göstergeler itibariyle değerlerinin düşük olması hiç şüphesiz Türkiye'deki üniversitelerin yapılanmasından ileri gelmektedir. Ele alınan ilaç sektörü

Tablo 1. Endüstriyel küme üyeliğine göre bağımsız T-testi göstergeleri.

Tablo 1. Indicators of independent T-test according to membership of industrial clusters.

\begin{tabular}{|l|c|c|c|c|c|c|c|c|}
\hline Gruplar & N & Ortalama & Std. Sapma & F & p & df & t & P (iki uçlu) \\
\cline { 1 - 5 } Küme üyesi olmayan & 37 & 0.1748 & 0.2146 & \multirow{2}{*}{1.891} & \multirow{2}{*}{0.170} & \multirow{2}{*}{231} & -2.730 & \multirow{2}{*}{0.007} \\
\cline { 1 - 5 } Küme üyesi buluşçular & 196 & 0.2868 & 0.2314 & & \\
\hline
\end{tabular}

Kaynak: Kaygalak ve Reid, 2016.

Tablo 2. Normalize edilmiş yakınlık kriterine göre bağımsız T-testi göstergeleri.

Tablo 2. Independent T-test indicators for normalized closeness measure.

\begin{tabular}{|l|c|c|c|c|c|c|c|c|}
\hline Gruplar & N & Ortalama & Std. Sapma & F & P & df & t & P (iki uçlu) \\
\cline { 1 - 5 } & 219 & 0.2685 & 0.2332 & \multirow{2}{*}{1.672} & \multirow{2}{*}{0.197} & \multirow{2}{*}{242} & -0.089 & 0.929 \\
\cline { 1 - 5 } Üniversite üyesi buluşçular & 26 & 0.2731 & 0.2253 & & & & & \\
\hline
\end{tabular}

Tablo 3. Üçlü kategoriye göre buluşçuların farklı parametreler itibariyle değerleri.

Tablo 3. Values of diverse parameters for the inventors according to triple categories.

\begin{tabular}{|l|c|c|c|c|}
\hline Gruplar & $\begin{array}{c}\text { Merkezi derece } \\
\text { (Degree) }\end{array}$ & Eigenvector & $\begin{array}{c}\text { Normalleştirilmiş } \\
\text { Yakınlık (ncloseness) }\end{array}$ & $\begin{array}{c}\text { Arasındalık } \\
\text { (Betweenness) }\end{array}$ \\
\hline Özel sektör & 1.6928 & 0.0142 & 0.2568 & 6.1831 \\
\hline Normal üniversiteler & 2.8901 & 0.0048 & 0.3289 & 0.0311 \\
\hline Teknik üniversiteler & 0.3552 & 0.0000 & 0.1609 & 0.0000 \\
\hline Significance (p<0.05) & 0.1641 & 0.6970 & 0.2103 & 0.7960 \\
\hline
\end{tabular}


(farmakoloji) açısından bakıldığında, Türkiye'de eczacılık bölümlerinin teknik üniversitelerden ziyade normal üniversitelerde ve çoğunlukla da kamu üniversitelerinde yer aldığı bilinmektedir. Bu yüzden ilaç sektörü açısından teknik üniversiteli buluşçuların değerleri daha düşük çıkabilmektedir. Dolayısıyla teknik üniversiteli buluşçulara ait söz konusu durumun ortaya çıkışı konu ve örneklem seçimiyle yakından ilgilidir. Ancak burada önerilen haliyle bu yöntemle farklı kategorideki üniversitelerin yenilikçilik süreçleri açısından farklılaşan konumunun sorgulanabileceğini göstermektedir. Bu yöntem kullanılarak teknik üniversitelerdeki bölümlerle bağlantılı sektörler için analiz yapılırsa, o zaman teknik üniversiteli buluşçuların yenilikçilik süreçlerindeki kritik rolüne dair daha anlamlı ve bağlayıcı sonuçlara ulaşılabilir.

\section{Sonuç ve Tartişma}

Bu çalışma özellikle Türkiye gibi patent ve diğer yenilikçilik göstergelerine dair verilerin az olduğu gelişmekte olan ülkelere dair niceliksel yöntemlere dayalı analizlerin geliştirilebileceğini göstermektedir. Yenilikçi bilginin üretimi ve yayılımının coğrafi boyutlarına dair incelemelerde çoğunlukla gelişmiş ülkelerdeki zengin veri kaynaklarına bağlı olarak yöntemler geliştirildiğinden, bu yöntemlerin bazen Türkiye gibi ülkelerde kullanımı mümkün olamamaktadır. Yukarıda da bahsedildiği gibi atıf verisi üzerinden hareketle yenilikçi bilginin yayılımını ve mekânsal boyutlarını Türkiye'de incelemek mümkün değildir. Bu yüzden bu çalışmada önerilen buluşçuların sosyal ağından hareketle incelemeler daha anlamlı ve açıklayıcı olabilmektedir. Daha da önemlisi patent verilerinden hareketle buluşçulara ait değişik niteliklerin tanımlanarak daha sonra gruplar arası farkılışmanın istatistiksel olarak test edilmesi, bu konuda yapılabilecek yegâne niceliksel analiz yöntemi gibi görünmektedir.

Çalışma, yenilikçi bilgi üretiminde üniversitelerin beklenilen düzeyde rol oynamadığını, üniversiteli buluşçuların yenilikçi bilgi üretim ağında zayıf konumda olduklarını göstermektedir. Özellikle teknik üniversiteler gibi araştrrma ve geliştirme faaliyetlerine odaklı eğitimi hedefleyen ve üniversite-sanayi işbirliği açısından kilit konumda olması beklenilen üniversitelerin bu anlamda daha da geride olduklarını göstermektedir. Bu nedenle ülkenin bilim ve sanayi politikaları çerçevesinde üniversite sanayi işbirliğini geliştirmeye dönük alternatif yolların aranması gerekliliğine işaret etmektedir. Öte yandan ilaç sektörü örneğinde bakıldığında özel sektör bazında da yenilikçi bilgi üretiminin belli başlı birkaç firma nezdinde yoğunlaşması da bir başka sorun olarak addedilebilir. Küçük ve orta ölçekli işletmelerin salt lisans bazlı üretim faaliyetleri değil fakat bunlara ilave olarak yenilikçi bilgi üretim süreçlerine doğrudan katılımı yönünde destekleyici mekanizmaların üretilmesi gerektiği görülmektedir.

Bunun yanı sıra buluşçuların sosyal ağından hareketle yenilikçi bilgi üretimi ve yayılımının değişik dinamiklerini sorgulamak, inovasyon konusunda Türkiye'de daha farklı yönleri ele alan değişik çalışmaların ve araştırma gündeminin oluşmasına kaynaklık edebilir. Coğrafi açıdan bu çalışmada ele alınan yöntem mikro düzeyde bir analizi temsil etmektedir. Ancak bu tür çaIışmaların genelleştirilip diğer sektörler için de yaygınlaştırılması durumunda ülkedeki inovasyon dinamikleri daha iyi anlaşılabilir. Ayrıca böylesi bir mikro analizin yanı sıra özellikle yenilikçiliği etkileyen kurumsal çerçeveye dönük orta ölçekteki çalışmaların yapılması gerekmektedir. Özellikle üniversite sanayi işbirliğinin buluşçu-aktörler düzeyindeki analizinin kurumsal perspektifle yapılan analizlerle birleştirilmesi, yenilikçiliği engelleyen koşulların daha iyi açıklanmasına ve anlaşılmasına yardımcı olabilir. Yine bu çalışmada kısaca değinilen, endüstriyel kümelerin ve yığılmaların yenilikçilikle olan ilişkisinin aynı zamanda bölgesel kurumsal yapıların niteliğiyle incelenmesine ihtiyaç duyulmaktadır. Dolayısıyla değişik perspektiflerden ve değişik sektörleri de içine alacak şekilde yenilikçi bilgi üretim ve yayılımının coğrafi boyutuna eğilmek gerekmektedir.

Çalışma kapsamında önerilen yöntemle yenilikçi bilgi üretim dinamikleri ile söz konusu bu bilginin coğrafi yayılımına dair başka konulara da açıklık getirilebilir. Bu kapsamda özellikle yenilikçi bilgi üretiminde yer alan buluşçuların coğrafi hareketliliği ile kurumlar arası hareketliliği izlenebildiğinden buluşçuların hareketliliğinin bilgi transfer süreçlerine katkısı da sorgulanabilir. Benzer bir şekilde coğrafi hareketliliğin etkisinin izlenmesi yenilikçi bilgi üretim sürecinde bölgesel düzeyde bilgi transferlerinin var olup olmadığını incelemeye imkân sunabilmektedir. Dolayısıyla yenilikçi bilgi üretiminde bölgeler arası işbirliğinin boyutları da incelenebilir. Yine patent dokümanları üzerindeki teknolojik sınıfların varlığı ve bundan hareketle yapılacak analizlerde yenilikçi bilgi üretiminde bölgesel düzeyde uzmanlaşmanın olup olmadığını, her bir bölgedeki yenilikçilik süreçlerine konu olan temel bilgi girdilerinin hangi alanlardan olduğunun analizine olanak vermektedir. Bu ise bölgesel düzeyde yenilikçi bilgi üretim sırasındaki bölgeler arası bağımlılık düzeyinin niceliksel olarak ölçümüne olanak verdiği gibi, her bir bölgeye özgü stratejik bilgi alanlarının belirlenmesini ve dolayısıyla buna uygun bir inovasyon politikasının geliştirilmesine olanak sunmaktadır.

Son olarak çalışma kapsamında kullanılan sosyal ağ analizi yöntemi Türkiye coğrafyacıları için nispeten yeni bir yöntemdir. Oysa ekonomik coğrafya başta olmak üzere nüfus araştırmalarında, göç çalışmalarında ve beşeri coğrafyanın diğer dallarında bu yöntem yabancı coğrafyacılarca sıklıkla kullanılmaktadır. İnovasyon coğrafyasını önerilen bu yöntemle çalışmak ve tanıtmak, sosyal ağ analizi yönteminin coğrafyacılar arasında kullanımını yaygınlaştıracağı gibi, beşeri coğrafyanın diğer alanlarındaki birçok yeni konuyu çalışmaya imkân verecek ve daha zengin bir araştırma gündeminin oluşmasına aracılık edecektir.

\section{Kaynakça}

Asheim, B., Coenen, L. ve Vang, J. (2007). "Face-to-face, buzz, and knowledge bases: sociospatial implications for learning, innovation, and innovation policy", Environment and Planning C 25: 655670.

Altınok, S., Mercan, B. ve Baltacı, N. (2004). "Öğrenen bölgeler: bölgesel kalkınmada ortak bilgi kullanımı”, 3. Ulusal Bilgi, Ekonomi ve Yönetim Kongresi Bildiriler Kitabı: 307-313, Eskişehir.

Audretsch, D. B. ve Aldridge, T. T. (2009). "Knowledge spillovers, entrepreneurship and regional development", R. Capello ve P. Nijkamp (Ed.), Handbook of Regional Growth and Development Theories içinde, s.201-210, Cheltenham: Edward Elgar.

Audretsch, D. B. ve Feldman, M. P. (1996). "R\&D spillovers and the geography of innovation and production", American Economic Review 86: 630-640.

Bathelt, H., Malmberg, A. ve Maskell, P. (2004). "Clusters and knowledge: local buzz, global pipelines and the process of knowledge creation", Progress in Human Geography 28: 31-56.

Boschma, R. A. (2005). "Proximity and innovation: A critical assess- 
ment", Regional Studies 39: 61-74.

Boschma, R. A. ve Frenken, K. (2010). "The spatial evolution of innovation networks. A proximity perspective", R. A. Boschma ve R. Martin (Ed.), The Handbook of Evolutionary Economic Geography içinde, s.120-137, Cheltenham: Edward Elgar.

Boschma, R.A. ve Ter-Wal, A.L.J. (2009) "Applying social network analysis in economic geography: framing some key analytic issues", Regional Science 43: 739-756.

Breschi, S. ve Lissoni, F. (2003). "Mobility and Social Networks: Localised Knowledge Spillovers Revisited", CESPRI Working Paper 142, Milan:University of Bocconi.

Capello, R. (1999). "Spatial Transfer of Knowledge in High Technology Milieux: Learning Versus Collective Learning Processes", Regional Studies 33: 353-365.

Cooke, P. ve Morgan, K. (1998). The Associational Economy: Firms, Regions and Innovation, Oxford: Oxford University Press.

Dulupçu, M.A., Sungur, O., Keskin, H., Sezgin, A. ve Demirel, O. (2010). "Bölgesel Kalkınmada Yeni Bir Kavram Olarak Bilgi Dinamiklerinin Rolü", 6. Ulusal Coğrafya Sempozyumu, Ankara Üniversitesi Türkiye Coğrafyası Araşttrma ve Uygulama Merkezi (TÜCAUM) Bildiriler Kitabı: 203-212, Ankara.

Durgut, M. ve Akyos, M. (2001). "Bölgesel İnovasyon Sistemleri ve Teknoloji Öngörüsü", Teknoloji Öngörüsü ve Stratejik Planlama Kongresi, 24-26 Mayıs, Sabancı Üniversitesi, İstanbul.

Eyyuboğlu, B.B. ve Aktaş, S.G. (2016). “Türkiye'de Teknoparkların Coğrafi Dağılım ve Yoğunluğu (2001-2015)”, Doğu Coğrafya Dergisi 21: 75-88.

Gertler, M. S. (2003). "Tacit knowledge and the economic geography of context or the undefinable tacitness of being (there)", Journal of Economic Geography 3, 75-99.

Giuliani, E. ve Bell, M. (2005). "The Micro-Determinants of Meso-Level Learning and Innovation: Evidence from a Chilean Wine Cluster", Research Policy 34, 47-68.

Graf, H. (2006). Networks in the Innovation Process, Local and Regional Interactions, Cheltenham-Northampton: Edward Elgar.

Gürsakal, N. (2009). Sosyal Ağ Analizi. Bursa: Dora Yayınları.

Hanneman, R. A. ve Riddle, M. (2016). Introduction to social network methods, http://faculty.ucr.edu/ hanneman/nettext/index.html. Son erişim 20 Aralık 2016.

Jaffe, A. B., Trajtenberg, M. ve Henderson, R. (1993). "Geographic localization of knowledge spillovers as evidenced by patent citations", Quarterly Journal of Economics 10: 577-598.

Kaygalak, i. ve Reid, N. (2016). "Innovation and knowledge spillovers in Turkey: The role of geographic and organizational proximity", Regional Science, Policy \& Practice 8: 45-61.

Knoben, J. ve Oerlemans, L. A. G. (2006). "Proximity and inter-organizational collaboration: a literature review", International Journal of Management Reviews 8, 71-89.

Krugman, P. (1991). Geography and Trade, Massachusetts-Cambridge: MIT Press.

Leydesdorff, L. ve Etzkowitz, H. (1996). "Emergence of a Triple Helix of university-industry-government relations", Science and Public Policy 23: 279-286.

Lundvall, B. A. (1992). National Systems of Innovation: Towards a Theory of Innovation and Interactive Learning, London: Pinter Publishing.

Mowery, D.C. ve Sampat, B.N. (2006). "Universities in National Innovation Systems", J. Fagerberg, D.C. Mowery ve R.R. Nelson (Ed.) The Oxford Handbook of Innovation içinde, s.209-239, Oxford University Press, New York.

Owen-Smith, J. ve Powell, W. W. (2004). "Knowledge Networks as Channels and Conduits: The Effects of Spillovers in the Boston Biotechnology Community", Organization Science 15: 5-21.

Piore, M. J. ve Sabel, C. F. (1984). The Second Industrial Divide: Possibilities For Prosperity, USA:Basic Books.

Powell, W. W., Koput, K.W. ve Smith-Doerr, L. (1996). "Interorganizational collaboration and the locus of innovation: Networks of learning in biotechnology", Administrative Science Quarterly 41:
116-145

Renski, H. (2012). "Using matched employee-employer data to measure labour mobility and knowledge flows in supply-chain and labour-based industry clusters", Journal of Regional Science Policy \& Practice 5: 25-43.

Soetanto, D. P. ve Geenhuizen, M. V. (2011). "Social Networks, university spin-off growth and promises of 'living labs", Journal of Regional Science Policy \& Practice 3: 305-321.

Sungur, O. ve Keskin, H. (2009). “Coğrafi Yakınlık 'Hala' Önemli mi ? Mekansal İnovasyon Modellerinden Çok-Yerelli Bilgi Dinamiklerine Dönüşüm", Akdeniz Üniversitesi Alanya İşletme Fakültesi Dergisi 1(2): 107-131.

Thompson, P. ve Fox-Kean, M. (2005). "Patent Citations and the Geography of Knowledge Spillovers: A Reassessment", The American Economic Review 95: 450-460.

Elçi, Ş., Karataylı, İ. ve Karaata, S. (2008). Bölgesel inovasyon Merkezleri: Türkiye Için Bir Model Önerisi, No: TÜSIAD-T/2008-12/477, İstanbul: TÜSIAD Yayınları.

Varol, C.., Sat, N.A., Gürel-Üçer, Z.A. ve Yılmaz, G. (2011). Yenilikçilik ve Mekan Ankara'daki Teknoloji Geliştirme Bölgeleri, No:MMO/546, Ankara: TMMOB Yayınları.

Wasserman, S. ve Faust, K. (1994). Social Network Analysis: Methods and Applications, Cambridge: Cambridge University Press. 
